Learning throughout working life: A relational interdependence between personal and social agency

\author{
Stephen Billett, Faculty of Education \\ Griffith University, NATHAN, 4111, Australia \\ Ph: $61-7-38755855$ \\ Fax: $61-7-38756868$ \\ Email: s.billett@griffith.edu.au
}

\author{
Key words \\ Learning for work \\ Professional development \\ Personal and social contributions to learning \\ Interdependence and learning \\ Social and personal agency \\ Running header \\ Learning throughout working life
}

\title{
Learning throughout working life: A relational interdependence between personal and social agency
}

Individuals actively and continually construct the knowledge required for their working lives. Two outcomes arise from this constructive process: (i) individual change (i.e. learning) and (ii) the remaking of culturally-derived practices comprising work. These arise through a relational interdependence between the contributions and agency of the personal and the social. The relationship is interdependent because neither the social nor personal contributions alone are sufficient. The social experience is important for articulating and providing access to 
work performance requirements. However, personal factors such as individuals' capacities, subjectivities and agency shape how workers interpret and engage with what they experience and, consequently, how they learn and remake practice throughout their working life. This case is elaborated through a discussion about learning with considerations of intersubjectivity, personal epistemologies, pedagogy and curriculum as experience. 


\section{Interdependence in individual learning and cultural change}

Learning throughout working life, as in professional development, can be understood in terms of participation in work activities and conceptualised as a negotiated (i.e. relational) interdependence between the social and personal factors. That is, learning is the process in and through which workers interact with the social experience they encounter in their workplace. Yet, this interaction is mediated by personal pre-mediate (i.e. earlier) social experience that shape how individuals interpret and construct what they experience in immediate encounters, such as through work. These pre-mediate social experiences are construed and constructed personally by individuals' cognitive experience and personal capacity, which in may reshape (i.e. change) that experience and capacity, as in learning. It is this sociohistoric person that negotiates the immediate social experiences in workplace settings. In a similar way, the immediate social experience of work comprising norms practices and techniques is founded on a wealth of required practices that have derived from their historic cultural enactment. The ways and means of conducting work carry cultural precedence that are supported, modified and abandoned as new and different practices and technologies emerge. It is this sociohistoric person that shapes what current work practices have become, that negotiates the immediate social experience of work. Therefore, and importantly, beyond the changes that may be described as workers' learning through this negotiation (for eg. becoming more competent through professional development), the same constructive and interactive processes also constitute the active remaking and transformation of the culturally-derived practices that comprises paid work.

Given this active and constructive process, the focus and direction of individuals' agency (i.e. their intentional actions) play key roles in the processes of learning and remaking cultural practices. The bases of this intentionality are likely to be located in individuals' subjectivities and capacities that arise from their socially- 
derived life histories or ontogeneses (Billett, Smith and Barker, 2005). Yet, its exercise occurs within an interdependence between the social and the personal. That is, workers need to engage in the socioculturally-derived and supported practices that make up the workplace in order to secure the knowledge required for work. While this necessity drives worker's learning and participation, the social practices that make up the workplace require workers to secure the purposes and goals of the workplace. In this way, workers' needs and practices of ongoing learning are interdependent with the goals and practices of the workplace. These two sets of contributions to individual (e.g. worker) and cultural (e.g. workplace) development (ie learning and change) are relational. On the one hand, an individual's potentially unique interpretations and enactments of the social suggestion of their work reveals limits to social agency That is, the capacity of the social world to secure its suggestion is neither comprehensive nor complete when and because it is limited by individual interpretation (Valsiner, 2000). On the other hand, individual's personal agency is conditioned by what possibilities of enacting their work affords them. In this way, individuals' freedom and capacity to secure their intentions is limited by the activities their work enables. Consequently, the negotiations between workers' pre-mediate experiences and immediate experiences of the workplace constitute a duality between personal and social agency best conceptualised as a relational interdependence (Billett, 2006a).

In particular, the relational character of individuals' capacities to influence the interdependence that substantiates this duality warrants deeper consideration. This is because it is only through their participation in and learning through work that the cultural transformations that comprise each changes to work practices can be enacted. This concern frames and is addressed within this paper. So, there is a need to go beyond accounts of learning that privilege situational contributions. Instead, a more comprehensive and convincing account of learning throughout working life needs to include and reaffirm the contribution and mediating role of individuals. 
These contributions are often absent or under-represented in contemporary conceptions such as activity systems (Engestrom, 1993), communities of practice (Wenger, 1998) and distributed cognition (Salomon, 1997). Acknowledging the utility of the socio-historical genesis of knowledge (e.g. Cole, 1998), its particular manifestation in instances of work practice and the situated character of competence (Billett, 2001) are all important. However, the current emphasis on the situated social experience is insufficient. It both misrepresents and under-represents how society's contribution to learning and human development is enacted. This contribution is also realised through an individual's unique socially-shaped life history or ontogeny. The legacy of ontogenetic development is individuals' cognitive experiences that mediate what they encounter through work and throughout working life. Further, accounts privileging the situational contributions to cognition may also ignore how brute facts (Searle 1995)(e.g. desire, age, disability, perceptual ability) make up part of their cognitive experience and shape workers' engagement with what is experienced. Through including individual contributions and mediation, the intent is to reinsert the 'subject' that is often missing or de-emphasised in contemporary accounts of learning. Moreover, in proposing the agency and uniqueness of the individual worker, a fundamental question for the social sciences is engaged - what brings about change: society or individuals? Here, personal and social changes are held to be realised through negotiations between both individual and social agency. In all, considerations of self and personal agency are brought centre stage to propose a more comprehensive account of the sociogeneses of knowledge, learning and the remaking of work.

These propositions are developed here by, firstly, proposing that the social geneses of knowledge are shaped by phylogenetic (historical), cultural and situational contributions; though their engagement and enactment are negotiated through individuals' moment-by-moment learning or microgenetic development. Then, the scope, potency and relational properties of the social contributions to 
learning and working are discussed. Following this, the role and extent of individuals' relations with the social world are proposed as reasons for restoring and re-emphasising individuals' role in conceptions of learning. The interdependence between social suggestion and individual agency is then elaborated, as is its relational character. In conclusion, a consideration of the self is advanced to assist conceptualising learning throughout working life or professional development, in terms of intersubjectivity, pedagogy, curriculum and personal epistemologies.

\section{The social geneses of knowledge}

As a starting point, it seems appropriate to elaborate a view about the geneses and exercise of the social contributions (i.e. gift of the social (Archer, 2000)) to the learning and remaking of work. This gift is generated and exercised through interaction between the contributions and agency of history, culture and situation, and individuals' knowledge and mediation, which are products of earlier sociallyshaped experiences and life histories. So, the sociogeneses of knowledge is held to be enacted through the immediate experiences in which it is encountered, yet personally mediated through construals and constructions founded in earlier experiences.

Sociocultural theory provides some helpful foundations to build an understanding of these knowledge sources and their enactment. It proposes that the activities individuals engage in and through which their cognition is shaped have historical and cultural geneses (Cole, 1998; Rogoff, 1990; Scribner, 1985a). Building on these foundations, five sources can be identified as contributing to the social geneses of knowledge, its enactment and transformation: (i) the phylogenetic - the evolving history of the human species; (ii) the sociocultural -- development that reflects a particular cultural need; (iii) situated practice, its particular form and requirements, (Billett 1998; 2001) as a manifestation of cultural practice (Suchman, 1997) and contributions to learning (Engestrom \& Middleton, 1996; Goodnow, 
1996; Lave, 1993; Rogoff, 1995); (iv) the microgenetic -- the moment-throughmoment learning occurring during individuals' engagement with the social world; and (v) ontogeneses -- the development of individuals' knowledge and ways of construing what they experience that arises through and throughout their personal histories (Scribner, 1985b) (see Figure 1). Together, these five interrelated and interdependent sources of development make up the sociogeneses of knowledge, learning and remaking of practice. That is, how the gift of the social (e.g. Archer 2000) is sourced, construed and remade. In the following sections, each source and its role is briefly elaborated in turn.

The phylogenetic source, firstly, is a product of the evolving history of the human species as expressed through the need for practices and concepts, such as communicating. This developmental level, which Vygotsky wanted to make into a social rather than a biological concept (Valsiner, 2000), is generated accumulatively through shared human experience in response to particular human needs through the development of cultural practices. For instance, the practices and purposes of communicating and calculating have developed and evolved through human history and stand as principles and practices that can be utilised when communication or calculation is required across a range of cultural practices (e.g. different kinds of work). In this way, the phylogenetic level informs diverse cultural practices about such needs, the processes for achieving them and for identifying commonly shared practices and concepts across these practices. The achievement of such broadly informing practices and principles are often held as important educational goals and are analogous to government inspired key or generic competences.

Figure 1 The sociogeneses and remaking of vocational practice (adapted from Billett 2003b)

Phylogenetic development (the evolving history of the species) Provides guiding concepts and procedures that are supra-cultural 


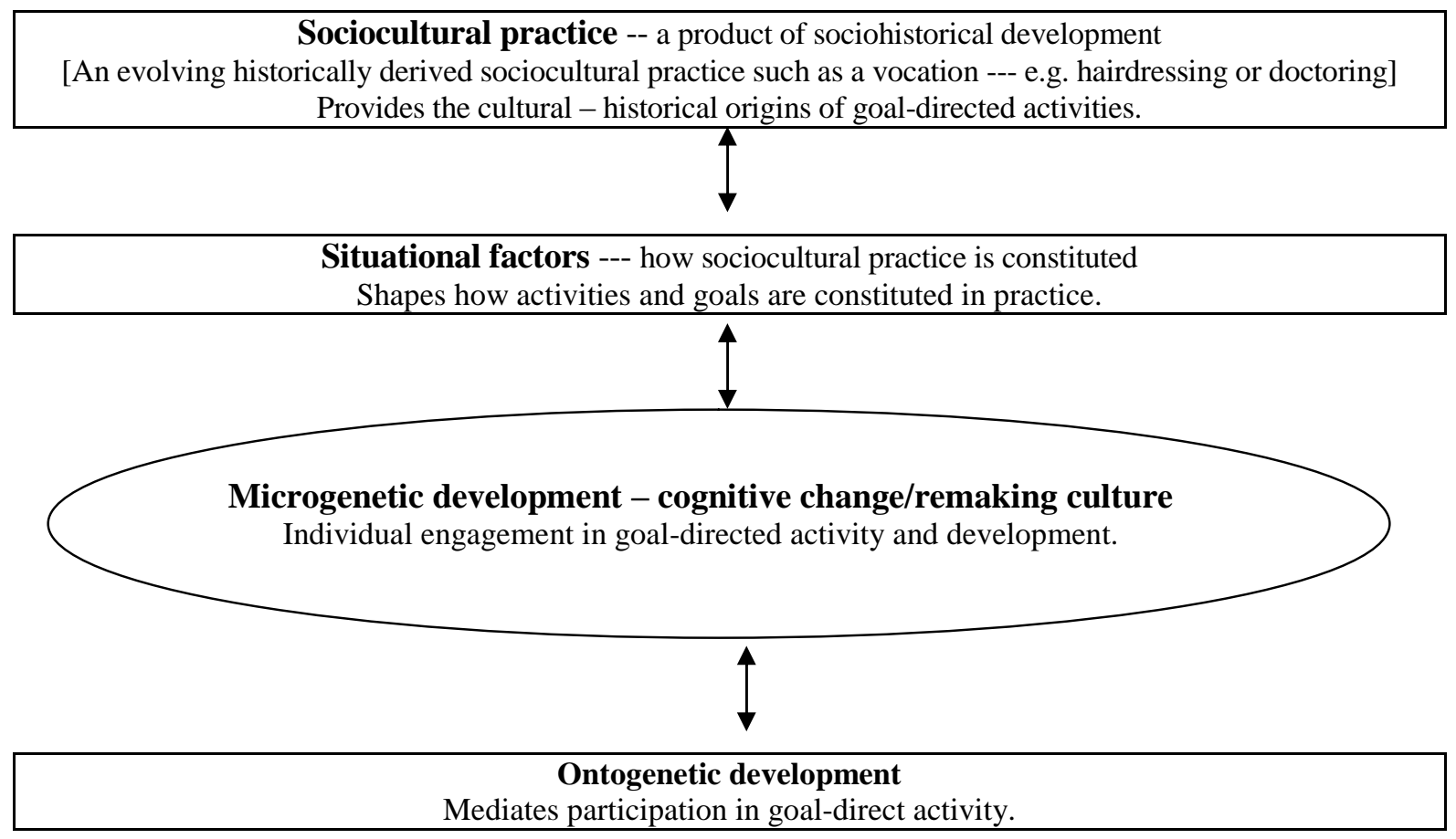

Secondly, sociocultural practices are those generated and remade over time in response to particular cultural needs shaped by cultural requirements and purposes (Scribner, 1985b) and usually comprise practices, values, technologies and norms. These practices elaborate the enabling qualities of socially-derived knowledge, as they respond to human needs. Each form of work represents an instance of these sociocultural practices that arise from particular human needs (e.g. for teaching, nursing, hairdressing) and that are required to transform over time, as needs and technologies change. They are subject to culturally-shared expectations, such as teachers being able to instruct and develop students' capacities, and identify their strengths and weaknesses. Similarly, doctors and nurses are subject to culturally-derived value-related expectations of confidentiality, fairness and acting in patients' interests. Such needs and expectations are inseparable from the cultural context in which they are generated and enacted (Scribner, 1985b), and can be manifested differently to reflect particular cultural requirements. For instance, the 
occupation of hairdressing has a different set of culturally and historically-derived practices to those of barbering. There are also diverse culturally-derived versions of hairdressing practice to be found, for instance, in salons in Chinatown (i.e. dark straight hair), trendy inner city salons (e.g. fashionable cut and colours) or a Rastafarian salon, with its particular approach to beading and styling. These versions of cultural practice arise from particular clientele's needs and warrant distinct concepts, practices and techniques. So, socioculturally derived occupational practices (e.g. doctoring, cooking, nursing, hairdressing) reflect and respond to particular, yet diverse cultural needs (e.g. styles of cooking and hairdressing) and can find variations in their manifestation within the same cultural context (e.g. country). In terms of educational intents, these cultural needs and their conceptions of competence are analogous to those expressed through documents aiming to organise the preparation of and regulation of occupational practice (e.g. national competency standards and national syllabus documents).

Yet, just as these curriculum prescriptions provide information about particular values, practices and expectations, the sociocultural level, remains abstracted from actual practice. Instead, situational factors shape how a culturallyderived occupational practice is ultimately constituted and enacted in particular work contexts (Billett, 2001). Consequently, there is the need to account for the local factors that shape how these culturally-derived practices are manifested and enacted. This represents the situational contribution to the sociogeneses of knowledge. Each workplace, even those enacting the same occupational practices, represents a unique instance of a vocational practice. So despite an occupational practice having its genesis in history and culture it is enacted, and therefore manifested by particular (and dynamic) sets of situational factors in particular workplace settings. For instance, the array of factors that shapes the enactment of work activities include workers' roles and preferences, division of labour, clients, location and layout (Billett, 2001; 2003b). Consequently, a hairdressing practice in a 
particular salon, at a particular point in time will have some unique characteristics (e.g. norms, work practices, clients, hairdressers). Even among culturally-derived variations (e.g. a trendy salon) there are likely to be situational variations in practice requirements. Similarly, for medical practice, the location (e.g. rural town, inner-city suburb, retirement community, remote Aboriginal community), its objects (e.g. characteristics of patients in terms of health, age, dispositions), how the practice is organised (e.g. shared practice, community-based, availability of doctors in rural settings) all shape how the practice is enacted and, therefore, its performance requirements. In these ways, although culturally-derived, the vocational practice and performance requirements that individuals encounter through their work only find tangible form when enacted in particular work settings. Therefore, as well as understanding the social sources of enactment of the knowledge required for work performance in terms of culturally and historically derived sociocultural practices, it is necessary to account for how vocational practice is constituted situationally.

Moreover, it is at the workplace where individuals experience work and learn through inter-psychological processes (i.e. between the social and the individual). In briefly elaborating this inter-pyschological process, its relational character becomes discernable. The social experience (Valsiner and van der Veer, 2000) that workers encounter comprises a range of socially-derived suggestions and enacted forms that are accessed during engagement in workplace activities and interactions. This immediate social experience is projected by the workplace practices, norms and discourses that constitute the requirements for performance at work, plus those who act within them, and material contributions in the form of socially-derived physical artefacts and tools encountered in the workplace. Yet, the experiencing of these social suggestions inter-psychologically is neither uniform, nor uniformly compelling. Instead, they are projected differently, in degree and intensity. Consequently, individuals find it either easier or more difficult to either appropriate or rebuff them. Certainly, in many, perhaps most instances (Valsiner, 2000) the 
social suggestions is not capable of securing either comprehensive intersubjectivity - shared understanding -- and faithfully reproduced practice (Gergen, 1994) or socialisation -- the subjugation of the individual to the immediate social suggestion (Foucault, 1979). Instead, both the agency of individuals and the social make particular contributions to workers' learning and their remaking of culturallyderived practices, such as their professional practice. So the contributions of the social world (the sociogenetic contributions) that shape learning comprise both what is experienced in the immediate experience and also that of individuals' lifelong engagement with social world.

Therefore, fourthly, and consistent with sociocultural theorising, learning is seen as an intra-psychological outcome or legacy - a product of individuals' engagement with social contributions - that occurs through moment-by-moment engagement or microgenetic development (Rogoff, 1990). For example, a midwife practising in a birth centre reports that through working closely with birthing mothers over time she developed a highly nuanced understanding of mothers' progress in the birthing process (Billett, 1999). She claims this understanding is distinct from that of gynaecologists who are less engaged in the entire birthing process, and often only extensively with difficult births. That is, each has had different sets of experiences, with particular legacies. There was also an identifiable legacy of hairdressers' participation in particular hairdressing practices and what constituted preferred performance (Billett, 2003b). Earlier and particular experiences shaped how hairdressers engaged in hairdressing tasks and constructed their hairdressing knowledge. These earlier experiences also shape how and with what intents individuals engage in work and working life. Disabled workers, for instance, face distinct challenges in engaging in and maintaining their capacity to participate in work effectively, for example, remaining relatively invisible and not making greater demands than able-bodied workers, lest they be characterised as liabilities (Church, 2004). 
The point here is that work is enacted and remade, and learning realised by humans as they deploy their capacities, interests and values in their work activities. These not things only exercised by a social practice. Indeed, there seems to be no common or objective basis for how work is enacted, because it is ultimately a subjective experience. Also, the motivating sense of satisfaction and self that individuals derive from participation in paid work is, at least, in part, person dependent (Noon and Blyton, 1997) and likely reflects a desire for ontological security (Giddens, 1991). However, this is not to advocate an 'anything goes' kind of relativism. Instead, individuals' subjectivities and sense of selves play a key role in their engagement in and valuing of their work and its further development. O’Doherty and Willmott (2001) propose individuals as working to identify and secure a 'sense of self' in their work. Therefore, given individuals' personal contributions to learning and cultural transformation, it is necessary to include how they elect to engage in and learn through their participation in work.

It follows that it is necessary to acknowledge contributions arising from individuals' ontogenetic development. Individual workers' personalities and ways of construing, constructing and engaging with what they experience in the immediacy of the social world, such as at work, are a product of a personally unique set of life experiences comprising a myriad of inter-psychological processes and intrapsychological outcomes. Consequently, the sociogeneses of vocational knowledge and learning include the deployment of historically and culturally-derived, yet situationally manifested social suggestions and their negotiations with individuals' ontogenies as depicted in Figure 1. These sources are held to be interdependent, rather than one subjugating the other. Although workers' intra-psychological outcomes will likely have some situational legacy, it is not a mere replication of workplace (situational) suggestions (Billett, 2001). Instead, they represent individuals' construing and re-making of what they experience. 
Additionally, it is at the situational level, that cultural practices are renegotiated and remade as individuals construe, remake and subsequently deploy them. This remaking necessarily occurs through the everyday work activities through microgenetic development (Rogoff. 1990). Individuals thinking acting is likely to be intentional and directed and can never be merely a faithful reproduction of what the social projects, because those projections are never complete or unambiguous (Berger and Luckman, 1966). So as individuals construe and construct meaning and enact their work practice they are also engaged in the ongoing and active process of constantly remaking practice as they engage in their work. Consequently, there is no separation between individual learning and this remaking. Giddens (1984) notes that social systems "do not reproduce themselves, they require the active production and reproduction of human subjects" (p. 114). It is this active process of learning and remaking of practices that bridges the historical heritage of human beings as each new generation takes over that heritage (Leontyev, 1981). Importantly, this process of learning "presents the learner as a constructor of new choices, not constrained to those in the immediate circumstances" (Valsiner, 1998, p. 114).

So, beyond the gift of the immediate social circumstance, is the energy, creativity and adaptability of individuals who participate in and adapt that knowledge to new circumstances (Baldwin, 1898; Valsiner, 2000). It follows that theories which view individuals as situationally-embedded (Engestrom, 1993), socially subjugated (Grey, 1994) or saturated (Gergen, 2000) fail to adequately account for their central role in the simultaneous processes of learning and remaking cultural practices. Therefore, accounts that emphasise the situation and not the subjects, are incomplete and ultimately unhelpful. The relations between the social and individual contributions need to be central to theories of learning. In order to understand these relations, it is necessary to consider how both the agency of the social and the individual are enacted. 


\section{The relational properties of the socio-geneses of knowledge}

Within theoretical accounts emphasising social contributions to knowledge and learning, there is a diversity of perspectives on the relationship between the social and individual. Some suggest that the individual is inevitably posterior to the social and is, at best, a placeholder for the social (e.g. Ratner, 2000). Others suggest that the relationship between the individual and social is more balanced (Giddens, 1984; Bhaskar 1998) or that the social suggestion is something that humans cannot deny (Archer, 2000) or wish away (Searle, 1995). Yet, despite its potential to shape human thinking and acting, the social suggestion is not always comprehensive or wholly compelling in pressing its gift (Giddens, 1991). Lave (1990) describes these practice-based, identity-forming experiences in her study of apprentice tailors living and working in their masters' houses and workshops, in a street of such workshops. These experiences were an apparently effective way of reproducing the practice of tailoring through processes of observation and imitation. However, as Lave and Wenger (1991) note, other kinds of workplaces may present less potent means for learning practice, because of the weaker potential for exercising socialising efforts. Moreover, individuals' capacity to interpret in a partial or particular way or even rebuff the social suggestion (Valsiner and van de Veer 2000) is recognition of the limits of its exercise. For instance, despite being subject to the close scrutiny of managers and owners, hairdressers were able to exercise personally-preferred options when engaged in hairdressing (Billett, 2003). Here, there is interplay between strong forms of social press and the individuals' mastery (e.g. accountants' apparent compliance (Grey 1994)) or appropriation (e.g. hairdressers' exercise of preference). Mastery refers to individuals' superficial and uncommitted compliance to the social practice, for instance in aspects of performance which are public (Wertsch, 1998). Appropriation refers to individuals taking up and becoming committed to what they encounter socially (Luria, 1976). 
Humans' unique capacities for reflective self-evaluation (Taylor, 1985) and exercise of reflexivity (McLaren, 1997) may free us from some forms of subjugation. Indeed, even when subjugated, our beliefs and conceptions are not able to be influenced by the most powerful social subjection. We might be forced into taking an action, but this force cannot control our beliefs and interests. Foucault (1986), for instance, claims no amount of surveillance can control human desire. Therefore, socialisation efforts such as attempts at securing the faithful transfer of knowledge from the social to the individual, as in intersubjectivity, are unlikely to be completely successful. The sociologists of knowledge, Berger and Luckman (1966) suggest that there are variations in how individuals conceive the social universe, even for those willingly engaging with the suggestion of the social, as with appropriation. This is because, on the one hand, the social world is not able to project its suggestion comprehensively or unambiguously, and, on the other, that individuals' engagement with the social will be distinct and characterised by difference. This difference, as noted, is a product of personal histories and individuals' attendant agency and the complex of factors that mediate their cognition.

Engagement in and learning from vocational practices, therefore, cannot be a mere reproduction of what is intended by social forms and encounters. This is not the least because it may be uncertain what has to be reproduced. The social suggestion may not be compelling enough and an individual's interpretation and construal might be quite different from the suggestion's intent and because suggestions cannot always be easily experienced in everyday life (Berger and Luckman, 1966). Instead, throughout working life, vocational practices may be elaborated, refined and remade by individuals as their agency and intentionality engages with socially-determined tasks and activities. Hence, the extent by which the suggestion of the social world is able to be exercised is relational. It is dependent upon its capacity to exercise its suggestion and the degree by which individuals take 
up that suggestion. This also suggests that cultural practices such as occupations are remade and transformed through a complex of ongoing interplays between each generation of individuals and the social world as meanings are made sense of, constructed, re-constituted and remade (Bhaskar, 1998; Gergen, 1994). The associations between this remaking and individuals' on-going learning it seems are irreducible. So, these relational qualities of the interdependence between the individual and the social need to be included in accounts that explain the ongoing process of learning through work and the evolution of occupational practices that reflect cultural imperatives and local need.

\section{The role of personal agency in relations with the social}

The contribution of personal agency in enacting, remaking and transforming culturally-derived practices is central to the regeneration and transformation of the knowledge required for work and its learning. Again, the literature that emphasises the social contributions to knowledge and learning provides some helpful accounts. For instance, a central tenet of cultural-historical activity theory (Cole, 1998) is that cultural practices have been developed and proven over time through collective processes (see Figure 1). However, Cole (2002), a key advocate of cultural-historical activity theory, concedes that personal agency is required to both enact and transform these practices. He noted that historically-derived classroom management practices were not helpful for his teacher education students' careers in tough and turbulent American high schools. He felt unable to advise his student teachers on how to proceed with their classroom practice. Instead, he suggested that the students would need to deploy their personal agency in remaking classroom management practices in the classrooms in which they teach. So, it is the agency of individual in adapting (i.e. remaking) and transforming historically-derived knowledge that is required to sustain and advance the sociocultural practice of teaching. Similarly, Vygotsky proposed that while engaged in culturally-derived acts of play, children 
contributed to their development in ways shaped by their interest and agency. He noted that when engaged in play, children extended their capacities in developmental ways, mediated by their own capacities. Moreover, it was the children, rather than their parents, who extended the scope of their development through their actions. That is, their agency extended prospects for the learning (Vygotsky in Valsiner and van der Veer, 2000). Here, Vygotsky, somewhat in contradiction to popular views of the Zone of Proximal Development implies that the potential for children's development is as much premised on individual agency as more experienced social partners.

Similarly, Baldwin (1930) proposed that human development occurs through “conscious and social accommodations, imitation, invention and volition ..." (p. 4). More than being passive, this imitation is exercised in particular and intentional ways reflecting the interplay between social experience (i.e. the source of imitation) and individuals' construction of what is to be imitated. Earlier, Baldwin (1894) concluded that from early interactions with their parents and others, children develop a 'social sense' and learn that these experiences can be unstable or unpredictable. He claimed that children learn from an early age of the uncertainty and unpredictability of their dealings with the social world. One day a request for a cookie is acceded to, the next rejected. This led to what he referred to as the projective stage in the growth of personal consciousness. In this stage, individuals actively deploy and extend their sense of knowing to monitor and comprehend the potential unpredictability of what they experience in social encounters. He (1894) proposed this development as being "indescribably subtle and indescribably inter mixed in the subjective ensemble of the growing child" (p. 275). It was through these earlier or pre-mediate experiences that "sense of personal actuation 'projective agency"' is formed. This is analogous to microgenetic development, exercised through what contemporary accounts propose as individuals' epistemological beliefs and agency (Smith 2006) and intentionality that directs the 
focus and effort of their conscious thinking and acting. Indeed, from observations of his own children, Baldwin (1898) noted that children come to exercise their private judgement, fight their own battles, and exercise both independence and the vice of obstinacy. That is, Baldwin claims that individuals learn this through selective engagement and negotiation with their social environment. Therefore, the exercise of these capacities arose as a social outcome, but premised on criteria of a personal kind.

Goodnow (1990) identifies a similar form of selectivity. She notes that individuals actively decide what problems are worth solving, thereby selecting which socially-derived tasks to engage in and how they should be engaged with, with consequences for their learning. She positions individuals as being actively engaged in their own development and the remaking of cultural practices (e.g. housework). In extending views about the agency and selective engagement of the individual with the social world, Valsiner (1998) proposes most human development occurs through individuals actively ignoring and neutralising the social suggestions they are subjected to in everyday life. This, he holds, is essential to buffer individuals' personalities against the constant demands of social suggestions. $\mathrm{He}$ proposes that efforts of socialising agents (e.g. institutions or parents) are of necessity countered by those who are subject to them, as they are able to ignore or neutralise most of these suggestions, except for the most compelling. Consequently, individual agency is not posterior or reducible to social agency. Instead, although not being able 'to wish it away', the individual can act independently of that suggestion. Taking Baldwin's (1898; 1930) view, individuals' engagement and negotiation with social suggestion (i.e. rebuttal or appropriation), necessitates acknowledging the importance of antecedents -- individuals' pre-mediate experiences. Gergen (1994), for instance, proposes that as we move through life we are continuously confronted by experiences offering new contexts and new challenges. "Yet our actions in each passing moment will necessarily represent some 
simulacrum of the past; we borrow, we formulate, and patch together various pieces of preceding relationships in order to achieve local coordination of the moment. Meaning at the moment is always a rough reconstitution of the past, a ripping of words from familiar contexts and their precarious insertion into the emerging realisation of the present." (pp. 269-270)

Further, while these personal constructions reflect the past, the agency and intentionality of individuals can also be directed towards the future. Two recent studies investigating workplace participatory practices over time (Author, 2004; 2005) found that much of workers' negotiation and enactment in their working lives could best be characterised as the exercise of individuals' intentionality towards them 'being themselves' as enacted through their agency. A sense of self was strongly articulated by these workers in most instances as providing agentic bases to 'be themselves' through their work. These findings reinforced the salience of these individuals' subjectivities, identities and processes associated with learning throughout working life. So, for these workers, the conception of self needed to be inclusive of propositions about achieving goals of personal autonomy, goals of increasing competence subjugations of the social suggestion to advance their plans for achieving these goals. Elsewhere, earlier experiences were identified as shaping how workers elected to engage in and attempted to transform their work practices and their working lives over time. These workers' earlier experiences provided the premises for their intentionality including how they interpreted and engaged with subsequent experiences: their knowing, ways of knowing, subjectivities, gaze and their epistemological beliefs. Their agency was directed by a quest to 'be themselves' in changing workplace circumstances.

Learning throughout working life, in this way, can be viewed as a negotiated, but transformative journey as individuals selectively negotiate their engagement in work, and changing work requirements, work practices and the shifting bases for participation in work. This includes reshaping their sense of self through the agentic 
ongoing and transformative practices of seeking the ontological security of 'being themselves'. So, individual workers are not mere and hapless hostages to the social experience. Rather, they are pressed to actively engage with it, even if only to rebuff it. It is these interplays that make up individuals' learning as they construe what they experience and construct a response that has legacies for both the individual (i.e. learning) and the workplace (remaking of practices).

More than just making contributions, in terms of their own knowledge, capacities and so on, individuals selectively shape their immediate social encounters and subsequent outcomes through personal volition and need for purposeful action. Hence, it follows that individuals need to be conceptualised as being personally agentic, yet socially shaped over time (Mead, 1913), albeit in potentially unique ways that arise from particular personal histories. Consequently, within this view, conceptions of subject and subjectivities shift from 'being placed under' to those in which individuals are viewed in terms of self and engaging in struggles for personal coherence and ontological security (Giddens, 1991), in ways analogous to the Piagetian (1968) quest for equilibrium.

\section{Relations in interdependence}

Having proposed an interdependence between immediate social experience and individuals and a relational bases for individuals' engagement and construction of this interdependence, it is necessary to explore the dimensions of these relational bases. In drawing on Baldwin $(1894,1898)$ it is evident that a relational bases between the individual and the social is far from a new consideration within cultural and socially-oriented psychological perspectives of learning. Similarly, from a sociological perspective, Giddens (1991) opposes a polarisation of agency and structure, viewing structures as enabling as well as constraining. Valsiner (1994) and Bhaskar (1998), although acknowledging the ubiquity of social influence, also emphasise the relatedness between individuals' interests and goals, and those 
comprising the social suggestion. It is this relatedness that stands at the centre of the inter-psychological processes through which individuals' learning and their remaking of practice arise. Consistent with this, Newman, Griffin and Cole (1989) claim that Vygotsky's greatest contribution was not in linking the external and internal, but in emphasising the dialectic between the inter- and intra-psychological. Here, it has been proposed (a) that the social suggestion is exercised with different levels of potency and (b) that individuals exercise different levels of responsiveness to social suggestion and by different degrees of engagement. For Valsiner (1994) this relatedness ranges from total involvement to being wholly disengaged. For instance, individuals may not even be aware of the social press, subjugation or discourse or other social forms in ways that influence the responses of others.

Often, the relations in inter-psychological processes are positioned as being reciprocal (Lawrence \& Valsiner, 1993; Rogoff, 1995), mutual, co-constructed (Valsiner, 1994), and co-participative (Billett, 2002). Indeed, a key claim from sociocultural theory is that as partners come together the idiosyncratic nature of their knowledge moves to be shared with partners (Griffin, Newman and Cole, 1989). Hence, intersubjectivity is seen as an important outcome of social interactions, particularly of the proximal kind. However, rather than being equal in their contributions, the interdependence between the social suggestion and individual agent is more likely to be relational in unequal, inconsistent and disjointed ways. This is because both individuals' scope for acting agentically, conceptualising what they experience in person-dependent ways and the potency of social suggestion, will differ depending upon circumstances, activities or interactions. Therefore, the intents, processes and outcomes of these interdependencies are so inherently subject to difference that claims about mutuality seem highly ambitious. Comprehensive intersubjectivity (i.e. shared understanding between situationally accessible knowledge and interlocutor) as in socialisation, stands as an unlike ideal as an intrapsychological outcome. The relational nature of this interplay suggests that equal 
personal or social contributions in inter-psychological processes and shared intrapsychological attributes and or outcomes as inter-subjectivity are rendered increasingly unlikely.

Furthermore, the lack of easy intersubjectivity renders as necessary individuals' need to remake the cultural practices they are engaged in, if for no other reason than their need to enact them with effect. Because it is difficult or impossible to provide unequivocal guidance about how a work task needs to be conceptualised and then enacted, individuals have to inevitably engage in remaking the culturallyderived practices that constitute their work. So when faced with a work task, whether familiar or new, individuals undertake the activity, by drawing variously upon their capacities and attempting to make sense of the task before them, as Gergen (1994) proposes. Within cognitive theory, this process is referred to as enacting approximations of tasks of be achieved (Anderson, 1982). The process of learning these tasks is held to be one of securing increasingly mature approximation of the targeted performance. However, even when externally observable performance might be seen to be the same or similar, there can be no confidence that the learning that ultimately delivers a performance is shared: intersubjectively. Instead, there is likely to be a quite idiosyncratic structuring of the knowledge that renders apparently similar performances (Billett, 2003a). Therefore, learning throughout working life needs to be seen as a relational concept, with the relationship being mediated by the personal agency and intentionality of the individual. This learning occurs as workers enact their subjectivity in attempts to secure and realise ontological security in changing work requirements. Such a view questions easy assumptions about intersubjectivity that are often central to considerations of instruction as individuals learn with some fidelity what they are being taught.

So, rather than simplifying or easing the constructivist project, the relational interdependence between social and personal agency make the construction of 
knowledge less easy to prescribe, describe or account for than, if they were reciprocal, mutual or co-constitutive in equal measures. These bases also make problematic prescriptions about instruction, suggesting instead a greater emphasis on curriculum as experience and pedagogy as being about personal epistemology. Hence, an instance of social practice, such as a workplace, needs to be understood in terms that include participants' interests, identities and subjectivities and their active role in the workplace's construal, construction and remaking. A consideration of relational interdependence attempts to open up and overcome dualisms in understanding subjectivities and self from definitions that are either overly centred on individuals, their feelings and behaviours or those relating to social structures.

\section{Self, competence and professional development}

In concluding, there is a need to look beyond situated accounts of learning and development in order to understand the learning throughout working life. This is because a worker's learning, identity and sense of self have been influenced in person-dependent ways from a history of relations with social practices. The consideration of the relational interdependence between the personal and social is not to propose a wholly phenomenological account of learning and instruction. Instead, it aims to place individuals, and their construction and sense making, and ultimately their subjective experience not only as a component of pedagogy and curriculum practice, but also as an inevitable outcome. In acknowledging the role that individuals' subjective experience plays in the curriculum process it is necessary to also acknowledge that that subjectivity, its transformation and trajectory stand as an important, inevitable and necessary outcome.

\section{References}

Anderson, J. R. (1982). Acquisition of cognitive skill. Psychological Review, 89 (4), 369-406. 
Baldwin, J. M. (1894). Personality-suggestion. Psychological Review, 1, 274-279.

Baldwin, J. M. (1898). On selective thinking. The Psychological Review, V(1), 1-24.

Baldwin, J. M. (1930). James Mark Baldwin. In C. Murchison (Ed.), A history of psychology in autobiography (pp. 1-30). Worcester MA: Clark University.

Berger, P. L., \& Luckman, T. (1966). The social construction of reality. Harmondsworth, Middlesex: Penguin.

Bhaskar, R. (1998). The possibility of naturalism. London: Routledge.

Billett, S. (1998). Situation, social systems and learning. Journal of Education and Work, 11(3), 255-274.

Billett, S. (1999). Experts' ways of knowing. Australian Vocational Education Review, 6(2), 25-36.

Billett, S. (2001). Knowing in practice: Re-conceptualising vocational expertise. Learning and Instruction, 11(6), 431-452.

Billett, S. (2002). Workplace pedagogic practices: Co-participation and learning. British Journal of Educational Studies, 50(4), 457-481.

Billett, S. (2003a). Vocational curriculum and pedagogy: An activity theory perspective. European Journal of Educational Research, 2(1), 6-21.

Billett, S. (2003b). Sociogeneses, activity and ontogeny. Culture and Psychology, 9(2), 133-169.

Billett, S. (2006a). Relational interdependence between social and individual agency in work and working life. Mind, Culture and Activity, 13(1), 53-69

Billett, S. (2006b). Work, change and workers. Dordrecht: Springer.

Billett, S. (2006c). Constituting the workplace curriculum. Journal of Curriculum Studies, 38(1), 31-48.

Billett, S., Smith, R., \& Barker, M. (2005). Understanding work, learning and the remaking of cultural practices. Studies in Continuing Education, 27(3), 219237. 
Church, K. (2004). Dancing lessons: A choreography of disability in corporate culture. Paper presented at the WALL Annual Meeting, Toronto.

Cole, M. (1998). Can cultural psychology help us think about diversity? Mind, Culture and Activity, 5(4), 291-304.

Cole, M. (2002). Building centers of strength in cultural historical research. Paper presented at the Annual Meeting of the American Education Research Association, New Orleans.

Engestrom, Y. (1993). Development studies of work as a testbench of activity theory: The case of primary care medical practice. In S. Chaiklin \& J. Lave (Eds.), Understanding practice: perspectives on activity and context (pp. 64103). Cambridge, U.K: Cambridge University Press.

Engestrom, Y., \& Middleton, D. (1996). Introduction: Studying work as mindful practice. In Y. Engestrom \& D. Middleton (Eds.), Cognition and communication at work (pp. 1-15). Cambridge, UK: Cambridge University Press.

Foucault, M. (1979). Discipline and punishment. New York: Vintage Books.

Foucault, M. (1986). The care of the self: The history of sexuality, vol. 3 (R. Hurley, Trans.). Harmsworth: Penguin.

Gergen, K. J. (1994). Realities and relationships: Soundings in social construction. Cambridge, Mass: Harvard University Press.

Gergen, K. J. (2000). The saturated self: Dilemmas of identity in contemporary life. New York: Basic Books.

Giddens, A. (1984). The constitution of society. Cambridge: Polity Press.

Giddens, A. (1991). Modernity and self-identity: Self and society in the late modern age. Stanford: Stanford University Press.

Goodnow, J. J. (1996). Collaborative rules: how are people supposed to work with one another? In P. B. Baltes \& U. M. Staudinger (Eds.), Interactive minds: 
Life-span perspectives on the social foundation of cognition (pp. 163-197).

Cambridge, UK: Cambridge University Press.

Goodnow, J. J. (1990). The socialisation of cognition: what's involved? In J. W.

Stigler, R. A. Shweder \& G. Herdt (Eds.), Cultural psychology (pp. 259-

286). Cambridge, UK: Cambridge University Press.

Grey, C. (1994). Career as a project of the self and labour process discipline.

Sociology, 28(2), 479-497.

Lave, J. (1990). The culture of acquisition and the practice of understanding. In J.

W. Stigler, R. A. Shweder \& G. Herdt (Eds.), Cultural psychology (pp. 259-

286). Cambridge, UK: Cambridge University Press.

Lave, J. (1993). The practice of learning. In S. Chaiklin \& J. Lave (Eds.),

Understanding practice: Perspectives on activity and context (pp. 3-32).

Cambridge, UK: Cambridge University Press.

Lave, J., \& Wenger, E. (1991). Situated learning - legitimate peripheral participation. Cambridge, UK: Cambridge University Press.

Lawrence, J. A., \& Valsiner, J. (1993). Conceptual roots of internalisation: From transmission to transformation. Human Development, 36, 150-167.

Leontyev, A. N. (1981). Problems of the development of the mind. Moscow:

Progress Publishers.

Luria, A. R. (1976). Cognitive development: its cultural and social foundations. Cambridge, Mass: Harvard University Press.

McLaren, M. A. (1997). Foucault and the subject of feminism. Social Theory and Practice, 32(1), 109-128.

Mead, G. H. (1913). The social self. Journal of Philosophy, Psychology, and Scientific Method, 10, 374-380.

Newman, D., Griffin, P., \& Cole, M. (1989). The construction zone: Working for cognitive change in schools. Cambridge, UK: Cambridge University Press. 
Noon, M., \& Blyton, P. (1997). The realities of work. Basingstoke, Hants: Macmillan.

Piaget, J. (1968). Structuralism (C. Maschler, trans. and ed.). London: Routledge \& Kegan Paul.

O'Doherty, D., \& Willmot, H. (2001). The question of subjectivity and the labor process. International Studies of Management and Organisation, 30(4), 112133.

Ratner, C. (2000). Agency and culture. Journal for the Theory of Social Behaviour, 30(413-434).

Rogoff, B. (1990). Apprenticeship in thinking - cognitive development in social context. New York: Oxford University Press.

Rogoff, B. (1995). Observing sociocultural activity on three planes: Participatory appropriation, guided participation, apprenticeship. In J. V. Wertsch, A. Alvarez \& P. del Rio (Eds.), Sociocultural studies of mind (pp. 139-164). Cambridge, UK: Cambridge University Press.

Salomon, G. (1997). No distribution without individuals' cognition: a dynamic interactional view. In G. Salomon (Ed.), Distributed cognitions: Psychological and educational considerations (pp. 11-139). Cambridge: Cambridge University Press.

Scribner, S. (1985a). Knowledge at work. Anthropology and Education Quarterly, $16,199-206$.

Scribner, S. (1985b). Vygostky's use of history. In J. V. Wertsch (Ed.), Culture, communication and cognition: Vygotskian perspectives (pp. 119-145). Cambridge, UK: Cambridge University Press.

Searle, J. R. (1995). The construction of social reality. London: Penguin.

Smith, R. (2006) Epistemological agency: a necessary action-in-context perspective on new employee learning. Studies in Continuing Education. 28(3), 291-304. 
Suchman, L. (1997). Centers of coordination: A case and some themes. In L. B. Resnick, C. Pontecorvo, R. Saljo \& P. Burge (Eds.), Discourse, tools and reasoning: Essays on situated cognition (pp. 41-62). Berlin: Springer.

Taylor, C. (1985). Human agency and language: Philosophical papers 1. Cambridge: Cambridge University Press.

Valsiner, J. (1994). Bi-directional cultural transmission and constructive sociogenesis. In W. de Graaf \& R. Maier (Eds.), Sociogenesis re-examined (pp. 101-134). New York: Springer.

Valsiner, J. (1998). The guided mind: A sociogenetic approach to personality. Cambridge, Mass: Harvard University Press.

Valsiner, J. (2000). Culture and human development. London: Sage Publications.

Valsiner, J., \& van der Veer, R. (2000). The social mind: The construction of an idea. Cambridge, UK: Cambridge University Press.

Vygotsky, L. S. (1978). Mind in society - the development of higher psychological processes. Cambridge, Mass: Harvard University Press.

Wenger, E. (1998). Communities of practice: Learning, meaning, andiIdentity. Cambridge, UK: Cambridge University Press.

Wertsch, J. V. (Ed.). (1985). Culture, communication and cognition: Vygotskian perspectives. Cambridge, UK: Cambridge University Press.

Wertsch, J. V. (1998). Mind as action. New York: Oxford University Press. 